\title{
A STUDY OF CHANGES IN THE SPINE IN WEIGHT LIFTERS AND OTHER ATHLETES
}

\author{
N. D. AGGRAWAL, FRCS, MCh, ${ }^{*}$ RAVINDER KAUR, MD, ${ }^{*}$ S. KUMAR, MB, BS, ${ }^{* *}$ D. N. MATHUR, MD广 \\ *Professor and Head of the Department of Orthopaedic Surgery, \\ Government Medical College, Patiala (India) \\ **Assistant Professor of Radiology, Government Medical College, Patiala \\ ***Post Graduate Student \\ tSenior Lecturer, Institute of Physical Education, University of Ife, Nigeria
}

\begin{abstract}
The present study was undertaken in sportsmen of those groups of sports activities where weight training exercises constitute a major part of the training. Two groups consisting of 25 weight-lifters and 25 track and field athletes were studied to find out the effect of sports activities and lifting weights on the spine. $84 \%$ weight-lifters and $72 \%$ track and field athletes suffered from varying abnormalities. Incidence of backache in $\mathbf{2 5}$ weight-lifters was $\mathbf{4 0 \%}$ and in 25 track and field athletes $48 \%$. Radiological changes were more common in weight-lifters $(84 \%)$ than in athletes $(72 \%)$. Reduction in lumbar lordosis was found in three cases $(12 \%)$ in both the groups. Obtuse angle deformity of vertebral margins was found in 11 cases $(44 \%)$ amongst weight-lifters and six cases (24\%) amongst athletes. Osteophytic formation was found in six cases $(24 \%)$ in weight-lifters and four cases $(16 \%)$ in athletes. Schmorl's node were noticed in five cases $(20 \%)$ amongst weight-lifters and seven cases $(28 \%)$ amongst athletes. The incidences of spondylosis and Schmorl's node were found only in those cases who had been doing weight training exercises for more than four years.
\end{abstract}

\section{INTRODUCTION}

Utility of physical training in promoting health, prevention of ailments and building-up of the body for competitive sports is well known. However, due to constant participation in sports and games, the sportsmen are more susceptible to injuries. Weight-training exercises may lead to many bodily injuries, out of which spinal injuries are of great importance. The present study has been conducted to observe the changes in spine in those sports events, which predominently use weight training exercises to improve their muscle strength.

Jaros and Cheh (1965) studied the spine of weightlifters and reported spondylosis in a weight-lifter. Similarly, Muenchow and Alber (1969) have also reported a solitary case of spondylosis amongst 32 weightlifters. Further, they observed obtuse angle deformity in eight cases, scoliosis of lumbar vertebrae in three cases and Scheuermann's disease in five cases. Kotani et al (1970) have also reported eight cases of spondylosis among 26 weight-lifters. They also noticed spondylosis among experienced weight-lifters.

\section{METHODS}

\section{Subjects}

Fifty subjects were elected from the National Institute of Sports, Patiala. Only those subjects, who were involved in physical activity for more than six months were included in the study. The subjects were divided into two groups of 25 each:-
Group A - comprised of weight-lifters only.

Group B - comprised of runners, jumpers and throwers.

\section{Procedure}

A thorough clinical examination of the subjects was carried out.

\section{History}

Detailed history of type of activity with duration, age at which activity was started and complaints, if any, were enquired into. In case of weight-lifters, detailed history of quantity of stress was laid on the history of backpain.

\section{Past History}

History of bony injury in the past was enquired. Personal and family histories were taken as a routine.

\section{General Physical Examination}

To find out any abnormality, a meticulous general physical examination of subjects was undertaken.

\section{Local Examination}

In every subject gait and deformity, if any, were noted. The spine was examined thoroughly.

\section{Radiological Examination}

In all the subjects radiological examination of the spine was carried out by taking antero-posterior and lateral 
views. The roentgen films were studied under the following headings:-

(i) Deformity

(ii) Density of bone

(iii) Height of the body of vertebrae

(iv) Margins of the body of the vertebrae

(v) Pedicels

(vi) Spinous processes

(vii) Transverse processes

(viii) Disc spaces and

(ix) Congenital abnormalities.

\section{RESULTS}

\section{Age Distribution:}

In group ' $A$ ' the average age was 31.5 years with a range of 17 to 38 years and in Group ' $B$ ' the average age was 27 years with a range of 17 to 32 years.

\section{Symptoms:}

Pain, particularly, low back pain was the only complaint in most of the cases. In group ' $A$ ' and ' $B$ ' 10 to 12 cases respectively complained of pain in the back. (Table I)

\section{TABLE I}

\section{Distribution of cases according to the} type of pain

$\begin{array}{lll}\text { Type of Pain } & \begin{array}{l}\text { Group A } \\ \text { No. of Cases }\end{array} & \begin{array}{l}\text { Group B } \\ \text { No. of Cases }\end{array} \\ \text { Persistent pain } & 4 & 5 \\ \text { Pain after activity } & 4 & 7 \\ \text { Pain during activity } & 2 & - \\ \text { Radiating pain } & - & -\end{array}$

\section{Deformity:}

Scoliosis was found in a solitary case amongst the weight-lifters (Group A), and reduction of lumbar lordosis was found in three cases or each group.

\section{Local Examination:}

i) Gait - Gait was found to be normal in all the subjects.

ii) Musculature - Well developed musculature was noted in all the subjects.

iii) Palpation and percusion: In Group ' $B$ ' only there was tenderness on palpation at the level of $D_{3}-D_{4}$ in one case and $D_{12}-L_{1}$ in another case. The roertogenogram of the region did not show any abnormality.

\section{Movements:}

Results of the study of movements of spine is given in Table II.
TABLE II

Results of movements of spine

\begin{tabular}{|c|c|c|c|}
\hline Range of Movements & Group & & Group \\
\hline & $\begin{array}{l}\text { No. of } \\
\text { Cases }\end{array}$ & $\%$ & $\begin{array}{l}\text { No. of } \\
\text { Cases }\end{array}$ \\
\hline Full movement & 18 & 72 & 21 \\
\hline Painful extension & 5 & 20 & 3 \\
\hline Painful flexion & 1 & 4 & 1 \\
\hline Painful rotation & 1 & 4 & - \\
\hline
\end{tabular}

\section{Radiological Examination:}

Numerous abnormal changes were noted in the roentogenograms of antero-posterior and lateral views of the lumbo-dorsal spine of all the subjects. Certain congenital abnormalities were also noted. All abnormalities are shown in Table III.

\section{TABLE III}

Summary of the results of roentogen examination

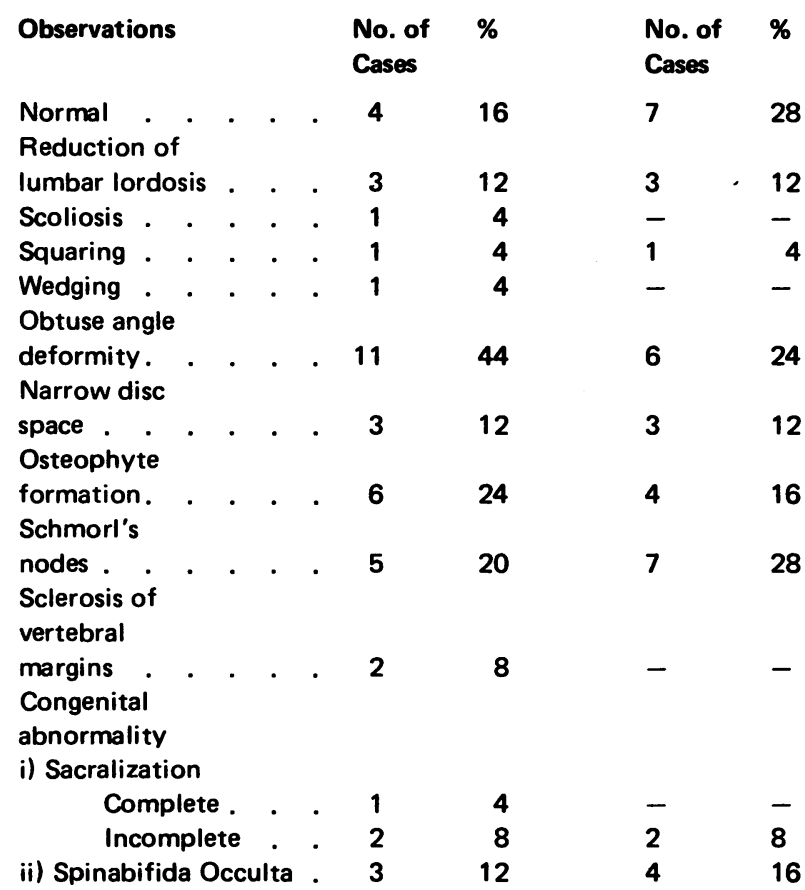

Relationship between clinical and radiological findings:

i) Cases with spina bifida

$\begin{array}{ll}\text { Group 'A' } & 3 \\ \text { Group 'B' } & 4 \\ \text { Total } & 7\end{array}$

All seven subjects complained of low back pain. In group 
' $A$ ' subjects, pain was felt only during activity and in group ' $B$ ' subjects pain was persistent and dull.

ii) Cases with Schmorl's nodes

$\begin{array}{lr}\text { Group 'A' } & 5 \\ \text { Group 'B' } & 7 \\ \text { Total } & 12\end{array}$

In group ' $A$ ' only two subjects complained of pain in the back and in one case extreme of extension was painful. Rest of the subjects had full range of movements.

In Group 'B', four subjects complained of pain in back after activity and only one subject complained of pain on extreme extension.

iii) Cases with osteophyte formation

$\begin{array}{lr}\text { Group 'A' } & 6 \\ \text { Group 'B' } & 4 \\ \text { Total } & 10\end{array}$

In group ' $A$ ', three subjects complained of pain in the back and in one case extension was painful.

In group ' $B$ ', three subjects complained of pain in the back and two cases had painful movements.

iv) Cases with narrow disc space

$\begin{array}{ll}\text { Group 'A' } & 3 \\ \text { Group 'B' } & 3 \\ \text { Total } & 6\end{array}$

In group ' $A$ ', all three subjects had pain in the back and in group ' $B$ ' two subjects had pain in the back after activity.

v) Subjects with wedging - in group ' $A$ ' - 1

This subject had pain in the back with extreme of extension painful.

\section{DISCUSSION}

Kotani et al (1970) reported low back pain in 24 subjects (92.3\%) out of 26 weight-lifters at some stage or other. While in our series, pain was detected in $44 \%$ of subjects. The individual abnormalities are discussed below:

\section{Spondylosis:}

The high incidence of spondylosis in weight-lifters and athletes may have some particular relationship between spondylosis and stress of lifting the weight. Kotani et al (1970) have reported a number of weight-lifters $(30.7 \%)$ developing spondylosis after four to five years of weight training activies. We too noticed spondylolytic change in weight-lifters and athletes with duration of activity of more than a period of four years. We also noticed that pain is not necessarily associated with such abnormalities. In our present study we found six subjects amongst weight-lifters as having osteophyte formation and out of them only two subjects complained of low back pain. Four athletes of track and field event showed osteophytic lipping with low back pain in three subjects. In normal population of the same age group the incidence of spondylosis is practically non-existent, thus we feel that this incidence of osteophyte formation in weightlifters and athletes is significant. Narrowing of a disc space was noticed in three subjects out of which two subjects complained of pain in the back region.

\section{Schmorl's nodes:}

Schmorl's nodes were observed in $20 \%$ subjects of group ' $A$ ' and $28 \%$ of group ' $B$ '. None of the subjects having duration of activity less than four years was found to have Schmorl's nodes. In normal population of the same age group, the incidence of Schmorl's nodes is quite low. Thus, we feel that the high incidence of Schmorl's node in weight-lifters and athletes is quite significant.

\section{Deformity:}

Reduction of lumbar lordosis was found in three cases (12\%) of each group. Scoliosis was found in a solitary case amongst the weight-lifters. Muenchow and Alber (1969) have reported three cases of scoliosis and reduction of lumbar lordosis in nine cases out of $\mathbf{3 2}$ weightlifters. Kotani et al (1970) also noticed more lordosis in normal adults than in weight-lifters. We attribute these changes as a compensatory mechanism in weight-lifters and athletes.

\section{Obtuse angle deformity:}

Eleven cases $(44 \%)$ of obtuse angle deformity of anterior edges of vertebrae were found amongst the weightlifters, whereas only six cases $(24 \%)$ were found amongst athletes. It was further observed that anterior upper edges were more commonly involved than the lower edges. We consider these changes as a compensatory process due to prolonged weight-training.

\section{Miscellaneous findings:}

A solitary case of squaring of the body of the vertebrae was found in both the groups.

Anterior wedging of the twelfth thoracic vertebra was found in a single subject. This we attribute to sudden increase in weights during weight training. jects.

Sclerosis of vertebral margins was found in two sub- 


\section{REFERENCES}

Jaros, M. and Cheh, U. M., 1965 Quoted by Muenchow et al, Medizin und Sport, No. 1, Berlin.

Kotani, P. T., Ichikawa, N., Wakabayashi, W., Yoshii, T. and Koshimune, M., 1970 "Studies of Spondylolysis found among Weight-lifters", Brit.J.Sports Med. 6: 4-8.

Muenchow, H. and Alber, H., 1969 "The Spine in Weight-lifters", Medizin und Sport, No. 1, Berlin.

\section{BOOK REVIEW}

Title: $\quad$ THE ROLE OF EXERCISE IN INTERNAL MEDICINE

Authors: D. Brunner and E. JokI. 1977. Vol. 10 of "Medicine and Sport"

Publisher: $\quad$ S. Karger, Basel. ISBN 3-8055-2362-9

181 pages including Index. 71 figs. 31 tables.

This book, like that edited by Edmund Burke, PhD, and reviewed also in this number, is multi-author, with again 24 contributors sometimes working in teams to produce 13 original papers. Whereas Burke collected papers from American and Canadian sports scientists and two doctors, Brunner and Jokl sought contributions largely from American, Israeli and European physicians of high repute, to produce excellent reviews of exercise in a variety of general medical conditions. Obviously much of the book is devoted to exercise and the circulation, but endocrine disorders including diabetes, infectious diseases and metabolic bone disease are also included.

As one would expect from a Karger publication, the production of the book is excellent; clear figures, standardised references, a rather scanty index, good binding, and the article reference given clearly at the head of each article.

These two books have provided me with fascinating holiday reading while watching the Mediterranean breakers lashing the Tunisian coast, and I have learnt a great deal from both of them.

H. E. ROBSON 